Received: December 14, 2017

Revision Received: June 12, 2018

Copyright @ 2018 EDAM

Accepted: June 15, 2018

www.estp.com.tr

DOI 10.12738/estp.2018.5.111 - October $2018 \cdot 18(5) \cdot 2115-2123$

Research Article

\title{
Innovative Physical Education Methods Based on Computer Technology
}

\author{
Xianzhou An \\ Luoyang Normal University
}

\begin{abstract}
As more importance is attached to physical education by the society, a variety of teaching aids and methods have been applied to physical education and also achieved remarkable results. Computer multimedia technology, as a frontier information technology, plays a decisive role in physical education and training. In this context, this paper analyses the effectiveness of computer multimedia technology in physical education. The research results show that computer multimedia technology has promoted the physical education significantly. This shall play a positive role in promoting the application of computer multimedia in physical education and training.
\end{abstract}

\section{Keywords}

Multimedia Technology • Physical Education • Control Simulation Application

Luoyang Normal University, Luoyang 471934, China. Email: anxianzhou@ 163.com

Citation: An, X. Z. (2018). Innovative Physical Education Methods Based on Computer Technology. Educational Sciences: Theory \& Practice, 18(5), 2115-2123. http://dx.doi.org/10.12738/estp.2018.5.111 
With the popularity of the Internet and the integrated development of computer information technology, campus teaching network belonging to the university itself is becoming more and more developed, more and more students begin to use the Internet to carry out their own learning and related work (Marina, Vassilis \& Panagiotis, 2011). So Network teaching in the daily teaching in colleges and universities is giving full play to its prominent advantage role, with which the applied subject scope is also more and more extensive.

Not only can multimedia network teaching simply make students actively learn to master knowledge and self-explore, but also more cultivate students' creative ability and innovative thinking.

Therefore, the significance of the promotion of multimedia network platform in physical education teaching of colleges and universities is summarized as the following points:

First, the popularization of multimedia network teaching platform in physical education teaching of colleges and universities makes sports teaching resources shared, advantages among different universities can complement each other (Garn \& Cothran, 2006).

Second, the popularization of multimedia network teaching platform in physical education teaching of colleges and universities has broken the traditional concept of students in colleges and universities for physical education, which makes understanding and learning on physical education of the students in colleges and universities reach a new height.

Third, the popularization of multimedia network teaching platform in physical education teaching of colleges and universities has broken through the traditional geographical limitations, which is not limited to the school, we can also take PE learning home (Tiffany, Pamela Hodges, Michalis \& Hans, 2013), to the community and even to any place where there is a network.

Fourth, the popularization of multimedia network teaching platform in physical education teaching of colleges and universities can effectively integrate the most advanced multimedia technology (such as: sound, image, text, pictures, graphics, animation), and can realize the simulation of the real environment (Shen, Li, Sun, \& Rukavina, 2010). The real-time communication and feedback between teachers and students can be carried out through the interaction of multimedia network teaching platform, and the problems can be found, put forward and solved in time.

Fifth, the popularization of multimedia network teaching platform in physical education teaching of colleges and universities is not a substitute for the traditional physical education teaching, but is a powerful supplement and assistance to the traditional physical education teaching. Teachers are the main body in most of the traditional physical education teaching which are carried out generally in the form of classroom and training. So students' autonomous learning and individual learning have been restricted by the field and facilities and teaching materials as well as teaching methods. However, the multimedia network teaching platform provides a powerful information database for students in colleges and universities, in which there is the latest global sports information, the most detailed technical action essentials and the most intuitive motion videos, through the use of interactivity, professional coach and expert's "close fitting" guidance can be achieved. At the same time, the multimedia network teaching platform has broken through the restriction of time and space, students 
can learn physical education even in out-of-class time, it complements with the traditional teaching method of teaching by words and influence by deeds, and is the development trend of modern PE teaching.

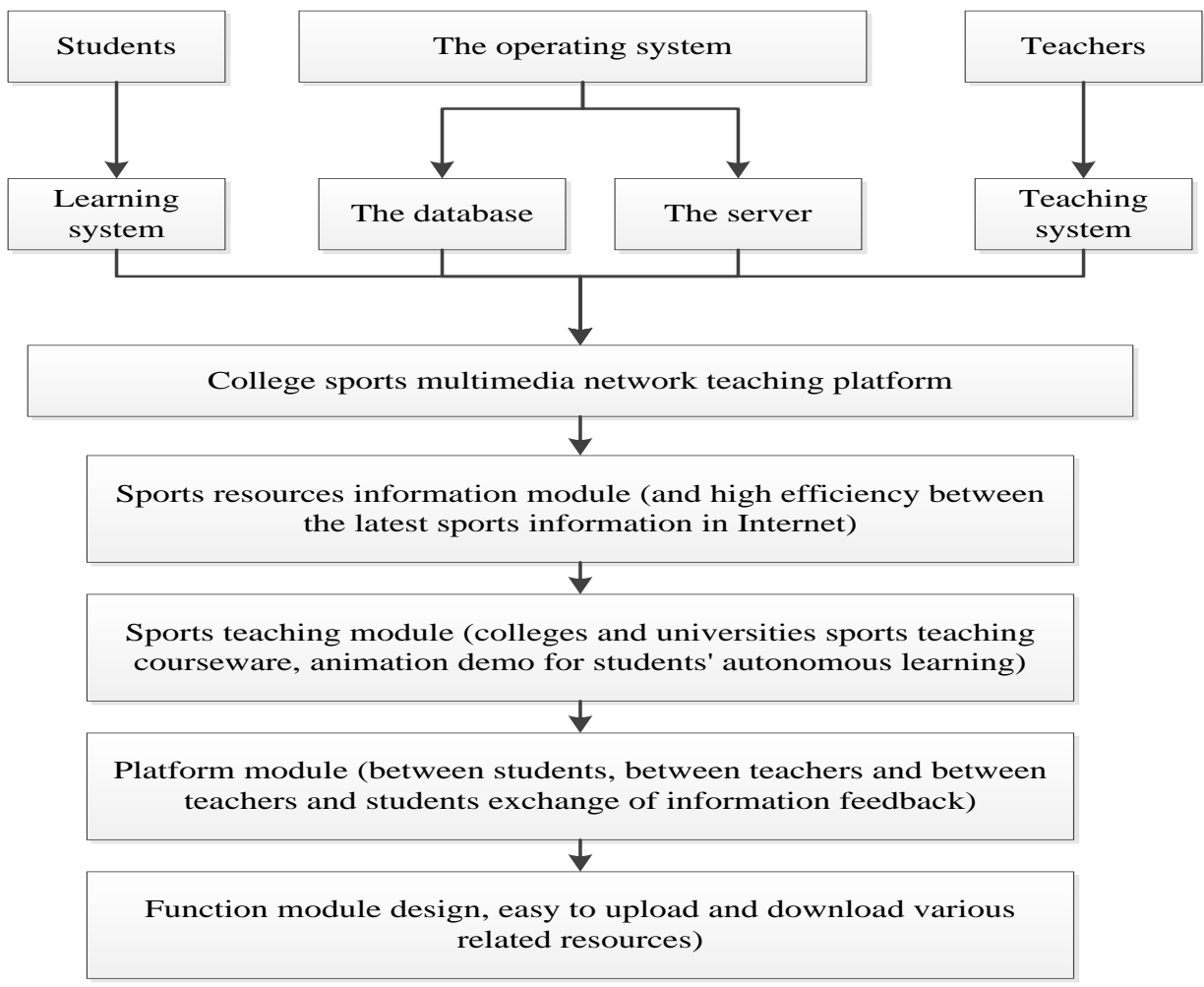

Figure 1. College sports support environment of multimedia network teaching platform structure

\section{Advantages of applying multimedia technology in physical education}

With the rapid development of information technology, multimedia technology is playing an important role in many fields. The application of multimedia technology in the field of education has greatly improved the quality of teaching. The application of multimedia technology in Physical Education Teaching has a breakthrough in progress, which effectively has solved the problem in teaching that has unsolved for many years, and has developed new teaching methods. The main advantages of applying multimedia technology in physical education teaching are mainly embodied in three aspects (Tim \& Ashley, 2014).

\section{Improvement of students' interest}

PE teaching is divided into two parts, namely theory teaching and outdoor sports training. The completion of traditional theory teaching is only by virtue of a teacher's mouth, a piece of chalk, a blackboard, combined with the students' listening to the lecture and making notes. The whole teaching process is boring, uninteresting 
and has nothing new. In traditional outdoor sports training, teachers' modelling, teachers' explanation and students' practice are taken as the main, normativity and systematic of the whole teaching process are bad and the overall level of physical education teaching is low, not achieving the purpose of the physical education. The multimedia technology is applied to physical education teaching, through the expansion of audio-visual information, high-tech expression, students' visual sense and hearing can be stimulated, effectively attracting students' attention, which makes the students focus on images, three-dimensional animation and video created by multimedia technology and other rich content of the teaching of physical education. And it makes PE teaching visualizing and three-dimensional, as a result, effectively increasing students' interest and motivating students to learn physical education from passivity to initiative (Alstot, 2012). The application of multimedia technology can stimulate students' interest in learning, improve students' theoretical knowledge on physical education as well as physical education, and can encourage students to have a healthy body and mind.

\section{Improvement of the learning effects}

The application of multimedia technology in physical education has played an important role, which is particularly evident in improving the learning effects. In the course of physical education teaching, the video, pictures, audio and other courseware's related to physical education made by multimedia technology are applied to physical education teaching, the vivid and visual courseware's are used to attract the attention of students(Chen, Hypnar, Mason \& Zalmout, 2014); through the courseware, a variety of sports will be threedimensionally shown to the students, instead of teachers' speaking, which can make students much easier to master the way and essentials of sports. The multimedia technology is used to carry out physical education, so the learning of physical education knowledge and training have been greatly improved, and learning effects are remarkable (Shen, McCaughtry, Martin, Fahlman \& Garn 2012).

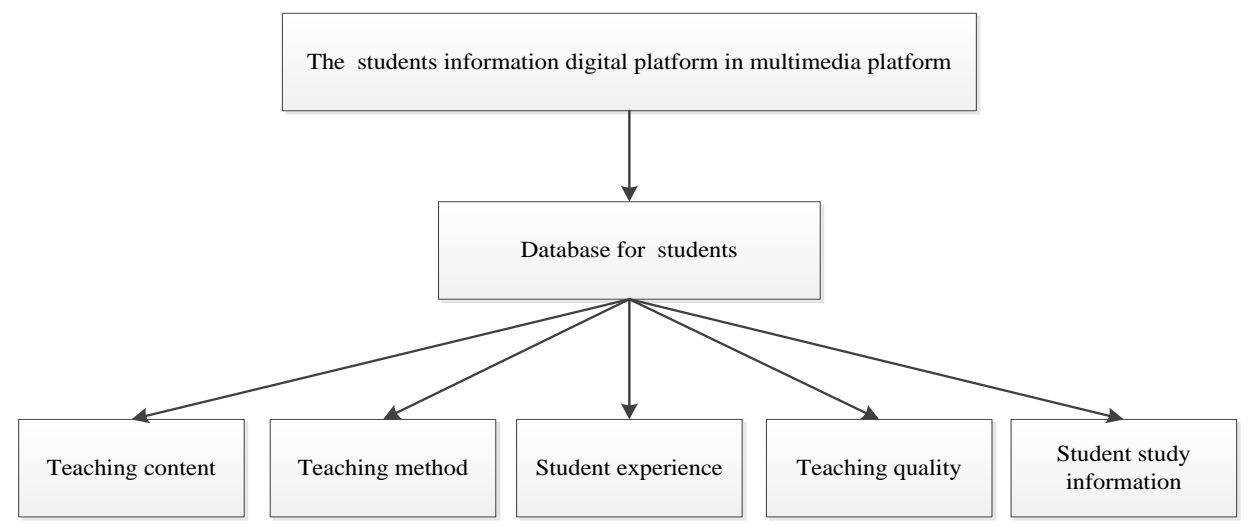

Figure 2. The student's information digital platform in multimedia platform

\section{Effective combination of multimedia and physical education teaching}

In physical education have always maintained the traditional teaching methods, and "cramming" teaching method is treated as the main, its scientific, innovation and pioneering are not strong. With the continuous development of economy in our country, education is taken as an important means of China's long-term 
development, so constantly improving the quality of teaching is one of the goals of every school. As one of the advanced scientific and technological achievements, multimedia technology is playing an important role in improving the quality of teaching, the application in the teaching of physical education can avoid many kinds of adverse factors in the teaching process, such as teachers' traditional teaching idea, the limited resources of the school, single teaching mode, etc.. The specific application of multimedia technology in physical education teaching is based on the traditional teaching mode, reasonable application of science and technology can make up for the shortcomings and disadvantages in traditional teaching, improving the effectiveness of physical education somewhat.

\section{Application of multimedia technology in the teaching of physical education}

Application of multimedia technology in physical education teaching is mainly shown as follows:

\section{Animation applications}

Applying multimedia technology to make animation is one of the major characteristics of this technology. The characteristics of multimedia technology shall be applied in physical education teaching, the production of teaching courseware can be completed through animation, which can encourage students, at the time of learning the theoretical knowledge of physical education, in the form of vivid animation, to acquire the teaching content shown by means of the movement, rotation, frame, slow, play, flicker, colour changes of graphics and animation combined with the simultaneous interpretation in its specific applications, enhancing the teaching effect. The expression of the teaching content through the form of animation can not only attract the students' attention, but also PE knowledge can be deeply imprinted in the minds of students, as a result, improving the students' PE knowledge level.

\section{Applications of video, audio, images and other materials}

It is a very common situation that video, audio, images and other materials are applied in multimedia technology. In the course of physical education teaching, these common materials in multimedia technology are applied to optimize the teaching content, greatly improving the teaching level of physical education. In the teaching of physical education, the specific application of audio, video, pictures and other materials of multimedia technology is that the teacher, according to the needs of physical education will make the movie and video related to the PE knowledge or online related information into teaching courseware's with teaching meaning through multimedia materials and use them in the classroom. When telling PE knowledge in the class, the teacher can further describe it through the application of the courseware consisting of video, audio, images, etc., improving the teaching effectiveness. 


\section{Control simulation application}

By using multimedia technology to achieve control simulation sports events, sports events to learn in sports classes are correctly acted out through the control simulation, which can contributes to students' grasping the standard operation of sports. In physical education teaching, teaching students to grasp the standard sports posture will lay a foundation for the follow-up sports training. Application of multimedia technology to achieve control simulation demonstration has fully expressed the relevant elements of the technical action and sports performance.

\section{Application of multimedia technology in physical education training}

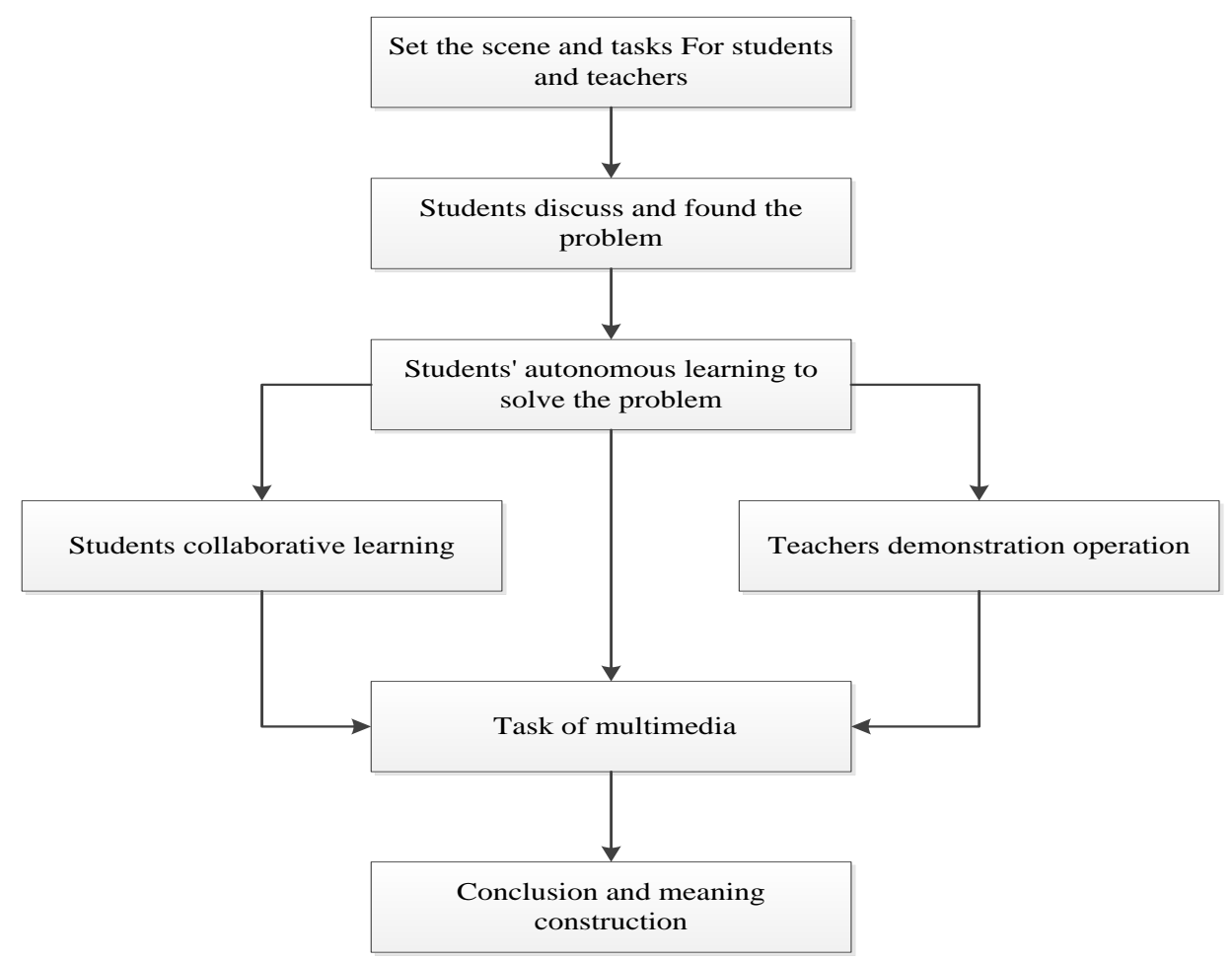

Figure 3. Teaching modes for multimedia

\section{Application of multimedia technology to optimize the demonstration link of sports events}

Demonstration is a kind of method often used in physical education teaching, it is that the teacher exercises the sports action to the student, which makes the students have an intuitive impression on the sports action, so that students can imitate and learn. In sports training, the Demonstration has a variety of types, such as mirror demonstration, demonstration of comparing right with wrong, local action demonstration, etc. Various types of demonstration have unique characteristics, and the difficulty is different, teachers' choice of demonstration 
method may not achieve the desired objectives, students are not able to fully grasp the correct standard action steps and action essentials (Mary \& Ben, 1994). In demonstration link of sports, the multimedia technology should be applied to improve the standard of demonstration. Because the application of three- dimensional images and synchronous interpretation materials in the media technology can reasonably show a variety of sports actions. When carrying out the demonstration link of sports in the implementation of sports training, the action of all kinds of sports events can be decomposed, displayed and simultaneously interpreted by threedimensional image, which can make the students master the action steps and the essentials of the sports events and play a positive role in promoting students' PE training.

\section{Simulated confrontational exercises}

In the process of physical exercise, the method shall be stressed; The confrontational exercise is applied in many sports, which has a great effect on the proficiency level of the improvement of sports. At present, the method of confrontational exercise is to choose an opponent with a certain technical characteristics to practice with, this way of confrontation exercises has a certain limitation, which is difficult to achieve in the absence of opponents. When the multimedia technology is applied to realize simulated implementation of confrontational exercises, its main application mode is to use multimedia technology to simulate the opponent with a certain technology level and the technology type, which can make your opponent have a certain "character" or "technical characteristics". Training personnel can continuously train their ability and level by the tactics that can be demonstrated in the multimedia technology to continuously improve their movement level.

\section{Test and calculation of applying multimedia to optimize physique}

The monitoring and evaluation of physique is the monitoring of the standard degree of sports events of middle school students in physical education. It is one of the essential events to carry out monitoring and evaluation of physique in physical education, by which the level of the physical and mental health of the students can be mastered to assist in the development of follow-up sports. Main contents of monitoring and evaluation of physique include the test of various sports, examination of physical ability of middle school students in medical room, calculation of test results, comprehensive evaluation, etc. In the process of monitoring and evaluation of physique, it is susceptible to a variety of adverse factors, so the accuracy of monitoring and assessment of physique is difficult to guarantee. Application of multimedia technology can solve various influencing factors of the physique evaluation. Multimedia technology has built a physique model, has analysed possible influencing factors in the process of monitoring and evaluation of physique and has determined the relationship between the physique type and other physique factors. In the course of monitoring and evaluation of the actual students' physique, the application of various influencing factors analysed by the multimedia technology shall be focused on, it shall be ensured as far as possible that the monitoring and evaluation of physique is accurate and reasonable.

\section{Creation of new technologies and new tactics}

Multimedia technology has many functions, such as combination, splicing, transformation and so on, the 
reasonable application of a variety of materials has made the multimedia technology become a good creation tool. This tool plays an important role in the training of sports events, mainly through which the technical and tactical innovation of sports has been completed. Using multimedia technology to innovate the technology and tactics of sports is mainly to simulate tactics and technology of sports events, after bold combination, splicing, transformation, etc., a variety of different types of technology and tactical has been created. In the test of newlycreated technologies and tactics, the final results are reasonable and effective. So the application of strong technologies and tactics can contribute to the improvement of the students' sports level.

\section{Conclusion}

By using multimedia technology to achieve control simulation sports events, sports events to learn in sports classes are correctly acted out through the control simulation, which can contributes to students' grasping the standard operation of sports. In physical education teaching, teaching students to grasp the standard sports posture will lay a foundation for the follow-up sports training. Application of multimedia technology to achieve control simulation demonstration has fully expressed the relevant elements of the technical action and sports performance.

Multimedia technology is the crystallization of the comprehensive development of modern science and technology. Application of multimedia technology has played an important role in strengthening physical education teaching and training, the application of multimedia technology in physical education teaching can improve the level of students' physical education theoretical knowledge, stimulate students' creative ability and dig the potential of students. The application of multimedia technology in physical education training can optimize the demonstration link of sports events, realize simulated confrontational exercises and optimize the test and calculation of physique as well as the creation of new technologies and new tactics. Only if the use of multimedia technology is constantly optimized to carry out physical education teaching and training can the students be better motivated to actively put their hearts into the study of physical education, finally promoting the realization of teaching goal of physical education.

\section{References}

Alstot, A. E. (2012). The effects of peer-administered token reinforcement on jump rope behaviors of elementary physical education students. Journal of Teaching in Physical Education, 31(3), 261-278. http://dx.doi.org/10.1519/JSC.0b013e318257807f

Chen, W., Hypnar, A. J., Mason, S. A., \& Zalmout, S. (2014). Students' daily physical activity behaviors: the role of quality physical education in a comprehensive school physical activity program. Journal of Teaching in Physical Education, 33(4), 592-610. http://dx.doi.org/10.1123/jtpe.2014-0060

Garn, A. C., \& Cothran, D. J. (2006). The fun factor in physical education. Journal of Teaching in Physical Education, 25(3), 281-297. http://dx.doi.org/10.1123/jtpe.25.3.281

Marina, P., Vassilis, G., \& Panagiotis, A. (2011). Multimedia blogging in physical education: effects on student knowledge and ict self-efficacy. Computers \& Education, 57(3), 1998-2010. 
http://dx.doi.org/10.1016/j.compedu.2011.05.006

Mary, O. \& Ben, D. (1994). Rules, routines, and expectations of 11 high school physical education teachers. Journal of Teaching in Physical Education, 13(4), 361-374. http://dx.doi.org/10.1055/s-2007-1021059

Shen, B., Li, W., Sun, H. \& Rukavina, P. B. (2010). The influence of inadequate teacher-to-student social support on amotivation of physical education students. Journal of Teaching in Physical Education, 29(4), 417-432. http://dx.doi.org/10.1123/jtpe.29.4.417

Shen, B., McCaughtry, N., Martin, J. J., Fahlman, M., \& Garn, A. C. (2012). Urban high-school girls sense of relatedness and their engagement in physical education. Journal of Teaching in Physical Education, 31(3), 231-245. http://dx.doi.org/10.1123/jtpe.31.3.231

Tiffany, K., Pamela Hodges, K., Michalis, S., \& Hans, V. (2013). Teacher fidelity to one physical education curricular model. Journal of Teaching in Physical Education, 32(2), 177-188. http://dx.doi.org/10.1346/CCMN.2007.0550207

Tim, F., \& Ashley, C. (2014). The challenges of models-based practice in physical education teacher education: a collaborative self-study. Journal of Teaching in Physical Education, 33(3), 403-421. http://dx.doi.org/10.1123/jtpe.2013-0109 